\title{
FUNCION DE LAS DIPUTACIONES PROVINCIALES EN LA DEFENSA DEL MEDIO AMBIENTE
}

\author{
$353: 581.52(46)$
}

\author{
por \\ José-Mario Corella Monedero
}

SUMARIO: I. REALIDAD Y FICCION DE LA DEFENSA DEL MEDIO AMBIENTE: 1. ConCePto DEL Medio ambiente. 2. Medio ambiente NATURAL Y MEDIO AMBIENTE ARTIFICIAL O MODIFICADO. 3. LOS ELEMENTOS DEGRADABLES.-II. LAS ACCIONES DE DEFENSA DEL MEDIO AMBIENTE: 1. SeCTORIALIZACIón. CONCURRENCIAS COM PETENCIALES. 2. LA POSIBLE INTEGRACIÓN A TRAVÉS DE ENTES DE FINES GENERALES.-III. LA ACCION ADMINISTRATIVA PROVINCIAL EN LA DEFENSA DEL MEDIO AMBIENTE: 1. ACTIVIDAD DE LIMITACIÓN. 2. ACTIVIDAD de PRESTACIÓN: A) Actividad de fomento. B) Actividad de prestación propiamente dicha. C) Actividad de coordinación.-IV. LA PLANIFICACION TERRITORIAL Y SU REPERCUSION EN LA DEFENSA DEL MEDIO AMBIENTE: 1. LA ORDENACIÓN DEL MEDIO COMO RACIONALIZACIÓN AMBIENTAL: A) En el medio ambiente urbano. B) En el medio ambiente rural.-V. ASPECTOS CONCRETOS DE DEGRADACION DEL MEDIO AMBIENTE: 1. POLUCIÓN DE LAS aguas. 2. ConTAMINACIÓN aTMOSférica. 3. Degradación de los suelos. 4. Otros tipos de Degradación. VI. CONCLUSIONES.

\section{REALIDAD Y FICCION DE LA DEFENSA DEL MEDIO AMBIENTE}

Como se ha puesto de relieve, el tema del medio ambiente no es de hoy, sino de siempre, aunque, no obstante, «es hoy cuando ha adquirido estado público, cuando se ha puesto de moda, cuan- 
do ha saltado al primer plano de actualidad con todas las ventajas $\mathrm{y}$, también, con todos los inconvenientes y con todos los peligros que esto lleva consigo» (1).

El problema del medio ambiente, y sobre todo la defensa del medio ambiente atmosférico, ha trascendido de la esfera técnica y ha pasado a dominio popular. Es raro el periódico que, de alguna forma y casi a diario, no se ocupa del tema. Pero en esta ocupación y en esa toma de conciencia que el hombre de hoy ha adquirido con respecto al medio ambiente, al entorno humano, puede que haya más de alarma que de verdadero planteamiento del problema medio-ambiental en su conjunto.

Ciertamente que éste no va a ser el tema de análisis aquí, sino que nuestra labor debe centrarse, concretamente, en cómo unos Entes locales, los. Entes locales intermedios, las Provincias, pueden actuar en defensa del entorno humano, y para ello hay que analizar lo que sea el medio ambiente, dejando a un lado determinaciones excesivamente amplias o conceptuaciones tan reducidas que harían perder al concepto su verdadera dimensión.

\section{CONCEPTO DEL MEDIo AMBIENTE}

Las peculiaridades nacionales estrechamente vinculadas con el desarrollo económico y social tienen que intervenir en la formulación de un concepto del medio ambiente (2) que, por ello, no puede ser uniforme para todos los países. En efecto, salvo en la etapa primitiva del hombre o, más genéricamente, del Mundo, el medio ambiente no es el mismo para cada grupo humano; en último término, el medio ambiente natural, el entorno en sentido amplio y considerado sin modificación alguna, no existe y sólo existió en los albores de la Humanidad. Simplemente por el hecho de aprovechar el fuego, surgido espontáneamente acaso, el hombre está modificando el medio, está incidiendo, de alguna forma, en una utili-

(1) Vid. FERNANDEZ RodRfGUEZ, T. R., El medio ambiente urbano y las vecindades industriales, Madrid, I. E. A. L., 1973, págs. 11-12.

(2) Vid. ANSÓN OLIART, R., aLa acción administrativa para la coordinación de la defensa del medio ambiente», en Revista de Estudios Turisticos, núm. 36, octubrediciembre 1972, pág. 553. En el mismo sentido, ARroyo GoMEz, M. A., en eInstrumentación administrativa para la coordinación de una política del medio ambientex, en Revista Internacional de Ciencias Administrativas, núm. 3, 1973, pág. 247. 
zación personal de uno de los elementos del medio ambiente y, en consecuencia, está alterando el equilibrio de todos ellos (3).

Por su parte, las condiciones geofísicas de cada país también influirán en la determinación del concepto particular que del medio ambiente se establezca, así como las circunstancias históricas, climáticas, hidrológicas, etc., porque, por ejemplo, el medio ambiente que hay que defender no es de la misma calidad -y la defensa será distinta- en Canadá, con sus enormes extensiones de bosques, que en Mauritania, donde predomina el desierto y unas diferencias térmicas considerables entre el día y la noche.

En consecuencia, podriamos definir el medio ambiente o usando otro término, el entorno humano, como «el conjunto, en un momento dado, de los agentes físicos, químicos, biológicos y de los factores sociales susceptibles de ejercer un efecto directo o indirecto, inmediato o mediato, sobre los seres vivos y las actividades humanas» (4).

Es, entonces, el conjunto de elementos que constituyen el cuadro, el medio y las condiciones de ejercicio de las actividades humanas tal como son o como se sienten, con la incidencia que tales actividades tienen en el mantenimiento de las condiciones de vida en nuestro planeta.

Así, el medio ambiente, el environnement francés, es el entorno, y ese entorno del hombre lo forman elementos varios que

(3) Vid. WARD, Barbara, y DuBos, René, Una sola tierra, México, Fondo de Cultura Económica, 2.: ed., 1972. «En fecha algo más reciente -dicen- empezó una intervención nueva y formidable: el uso de energía no humana para incrementar la actividad humana. En tiempos muy remotos, el hombre aprendió a valerse de los animales para que le ayudaran a realizar su trabajo. Pero con el uso del fuego empezó sus experimentos con los vastos recursos de energía no animal de la Tierran (pág. 33).

«El fuego ayudó a hacer claros en la selva y a fertilizar los campos; el fuego fundió los metales. El fuego calentó el hogar. Su uso, al ayudar a proporcionar un excedente, por encima de la mera subsistencia, preparó el terreno para los primeros experimentos en gran escala de una civilización organizada: en el Oriente Medio, en el norte de la India y en China. Sin embargo, en una de las más antiguas mitologías occidentales, el fuego no es considerado como un don benéfico. Es algo robado a los dioses, y Prometeo, el ladrón, es encadenado a una roca desnuda, con un buitre que le desgarra las entrañas como venganza por el sacrílego acto. Con este nuevo poder y capacidad para moldear su medio ambiente, se ve al hombre en la mitología griega desempeñando un papel divino, creador, innovador, rehacedor de su mundo y de sí mismo. Esto constituye su dignidad y su libertad. Pero es, potencialmente, el camino del arrogante orgullo, de una arrogancia que fácilmente se desborda hacia el riesgo de destrucción» (pág. 34).

(4) Definición propuesta por el grupo «Environnement-nuisances», del Comité Internacional de la Lengua Francesa. Vid. Le rôle des pouvoirs locaux en matière de sauvegarde de la Nature et de l'environnement, de J. B. VILMORIN. Publicaciones del Conseil de l'Europe, 1971, Collection Sauvegarde de la Nature. 
condicionan las actividades del individuo o se ven condicionados por ellas. En el entorno juegan factores naturales y factores artificiales, juega el paisaje rural y el paisaje urbano, el ambiente atmosférico natural y el ambiente atmosférico contaminado pero tolerable, las aguas potables y las aguas residuales, los productos silvestres y los productos cultivados. Por ello, al medio ambiente tiene que conceptuarse hic et nunc, y su degradación será tanto más importante cuanto más lejana sea la fecha de comparación o cuanto más incida el hombre en aglomeración sobre un territorio determinado.

Y las acciones medioambientales tratarán de defender el entorno actual o, avanzando en su misión, pretenderán retrotraer el entorno a un estadio anterior, pero nunca podrán llegar a un ambiente natural, inalcanzable, por definición.

\section{MEDIO AMBIENTE NATURAL $Y$ MEDIO AMBIENTE ARTIFICIAL O MODIFICADO}

De lo anteriormente expuesto, se hace necesario pasar a la conceptuación de lo que sea medio ambiente natural y medio ambiente artificial o modificado.

Inicialmente, el medio ambiente natural únicamente puede ser pensado en las épocas más primitivas de nuestro mundo, cuando el hombre, por su propia actividad, no había producido ninguna alteración artificial de su entorno. $\mathrm{Y}$ era así porque las actividades humanas quedaban reducidas a la caza, que proporcionaba comida y vestido. En la lucha por la vida morían los seres menos dotados y permanecían los más fuertes. El equilibrio ecológico se mantenía con un número limitado de individuos en cada especie. La alteración de ese equilibrio se produce cuando una de las especies empieza a crecer o a desaparecer sin un paralelo crecimiento o desaparición de las restantes, y es entonces cuando esa alteración del equilibrio ecológico produce modificaciones en el entorno. Cierto que tales modificaciones pueden deberse a causas naturales, en cuyo caso su estudio no nos afecta, pero también se deben a causas no naturales, a actividades del hombre que, poco a poco, va cumpliendo su misión de usar de la tierra para sí.

Así, paulatinamente, el medio humano, el medio en que el hombre se desenvuelve es fundamentalmente artificial, conformado por 
el mismo hombre — desde la cabaña hasta la gran ciudad-. La primera modificación del entorno humano surge con dos finalidades: la de protección y la de abrigo. La vivienda y el uso y producción consciente del fuego son las primeras incidencias perturbadoras del medio ambiente natural debidas al hombre; y las edificaciones y la combustión de diferentes materias van a ser los elementos más perturbadores en el medio ambiente o en el entorno humano hasta nuestros días.

No cabe duda que llegaríamos a situaciones absurdas si contraponemos absolutamente «entorno humano» y «desarrollo» (5). No puede detenerse el desarrollo para proteger de manera absoluta el medio ambiente (6) ni, por el contrario, pueden mantenerse niveles de desarrollo tecnológico sin tener en consideración las exigencias de la conservación del entorno. Pero tampoco puede ponerse en tela de juicio que es el hombre, con su actividad, quien produce una mayor degradación de su propio entorno, del medio en que normalmente se desenvuelve. Tal degradación, lógicamente se produce con mayor intensidad en las agrupaciones humanas, cuando en el mismo lugar y al mismo tiempo se producen acciones iguales o similares de ataque al medio.

Si esto es así en términos generales, mucho más lo es en la época moderna cuando los elementos técnicos, las máquinas de que cada hombre dispone, suponen, como dice Barbara WARD, una incidencia en el medio que representa la degradación que producirían 400 personas. Es como si cada uno de nosotros tuviera cuatrocientos esclavos $y$, en consecuencia, nuestra incidencia en el entorno se produce de forma más intensa (7). En definitiva, el hombre rom-

(5) Al hablar de adesarrollo» pensamos en el económico, industrial y tecnologico.

(6) Sin embargo, se está hablando ya, en algunos países, de desarrollo 0 .

(7) Vid. WARD, Barbara, y DuBos, René, Una sola tierra, ob. cit., donde afirman (pág. 38): «Una manera de ver esta gran expansión de las oportunidades personales ha sido sugerida por el Dr. Buckminster Fuller, quien hace treinta años hizo un cálculo de la cantidad de energía muscular necesaria para producir los abastecimientos de energía entonces disponibles, y sugirió que cada norteamericano contaba con el equivalente de 153 esclavos que trabajaran para él. En la actualidad la cifra sería probablemente más cercana a 400 esclavos, que se dedicarian a lo que tradicionalmente hacían los esclavos: efectuar las labores domésticas ligeras, cocinar alimentos, transportar a las personas, llevar y traer rápidamente abanicos y calentadores, entregar prendas de vestir, galas y ornamentos que habrían producido ellos mismos, tocar continuamente música, ruidosa o suavemente, según se les ordenara, y retirar los desperdicios de la vecindad inmediata. Ahora ya no se trata de hombres, sino de artefactos mecánicos, y en el centro de algunos de los más urgentes problemas en el medio humano - los problemas de la contaminación - se encuentran el espacio que ellos ocupan, la energía que 
pe el equilibrio ecológico, planteando el problema de su recomposición y la acción de recomposición - no del medio ambiente na. tural, sino de un medio ambiente artificial estandarizado o convencional pero tolerable - debe estar integrada en una estrategia del desarrollo y éste debería someterse a las exigencias fundamentales del entorno (8).

Por ello, y pensando en ese medio ambiente o entorno artificial (modificado, pero utilizable, con tendencia hacia lo natural), habría que buscar su dimensión espacial: cómo el entorno, el medio en que el hombre se desenvuelve, es proyectable espacialmente. Ėsa dimensión espacial del medio ambiente humano de alguna forma se nos manifiesta como una ordenación, un urbanismo, de tal manera que la salvaguarda y la defensa del equilibrio ecológico y la utilización de los espacios, al planificarse, entran a ser materia propia de lo urbanístico (calificación del suelo) al tiempo que tienden a conseguir un mejoramiento de la calidad de la vida. El urbanismo, entonces, deberá prever la defensa de determinados terrenos, su conservación en estado natural en forma que sean útiles para la comunidad toda, y tales espacios naturales podrían tener la consideración de bienes d'environnement, con una clara protección por parte de la comunidad de tal manera que su conservación pudiera considerarse como un costo social (9).

\section{Los'ElEMENTOS DEGRADABLES}

Hay, actualmente, una ambientación general nacida de la óptica parcial desde la que se contempla, en los medios de difusión, el

consumen y los desperdicios que producen. Pero todo esto es debido a la masa de gente que quiere sus "esclavos energéticos" y encuentra agradable la experiencia de la riqueza personal».

(8) Cfr. PERrot, Hubert, aEnvironnement y action administratives, en Administration, núm. 78, publicación de l'Association du Corps Préfectoral et des Hauts Fonctionnaires du Ministère de l'Interieur, París, enero 1973. «C'est pourquoi l'environnement doit être intégré à une stratégie du développement et le développement se soumetre à des exigences fondamentales d'environnement. Prende conscience des problèmes de l'environnement implique donc une réflexion attentive sur les conditions du développement industriel, agricole et urbain dans les sociétés modernes. Cette prise de conscience est liée à la redécouverte du milieu naturel que nous faisons actuellement après l'avoir oublié lors de la première révolution industrielle» (pág. 19).

(9) Vid. PERrot, ob. cit., pág. 20. a... es preciso encontrar -dice- un medio de no penalizar, ver de remunerar a los poseedores de tierras vírgenes o poco constructibles que son útiles en su estado a la colectividad, a fin de que estos poseedores de "bienes d'environnement" no tengan interés en transgredir las servidumbres de interés general que pesan sobre sus fundos». 
problema, que tiende a identificar defensa del medio ambiente con limitación de la polución atmosférica.

Sin embargo, con ser importante la lucha contra la contaminación por emanaciones gaseosas, humos y polvos, quizá su defensa pueda encuadrarse en límites de factibilidad tecnológica y legal. Sin duda los humos y gases pueden depurarse antes de ser lanzados a la atmósfera de manera que pierdan su nocividad o la limiten considerablemente.

Lo mismo ocurre con la contaminación de las aguas, pues cualquier emisión a un cauce público o al mar puede, previamente, estar depurada (10), y el control de esa depuración es relativamente fácil. Cierto que al reunirse miles y miles de personas en los núcleos urbanos las emisiones colectivas de residuos líquidos, unidas a las nacidas de las industrias, provocan una contaminación de las aguas, pero las autoridades municipales, de una parte, y los responsables de la industria, de otra, pueden proceder a establecer elementos y sistemas de depuración de manera que tal contaminación sea limitada o nula.

Sin embargo, piénsese que cuando hablamos de contaminación de las aguas, y fundamentalmente de las aguas fluviales, hemos de considerar, en todo caso, que tal contaminación no proviene exclusivamente de la composición de los efluentes, sino también de su temperatura. La elevación térmica que se produce en las aguas de un cauce público puede provocar una contaminación por destrucción de las reservas biológicas, tan fuerte como la derivada de la composición cualitativa o cuantitativa de los efluentes (11).

No obstante ser importantes estas formas de degradación de los elementos citados, la contaminación de la tierra tiene mayor importancia y desde varias perspectivas. El problema de la eliminación de los residuos sólidos, de los desperdicios, es un problema de envergadura que provoca serias dificultades. En primer lugar, la composición de las basuras - que varía según el tiempo y según las latitudes- hace que no sea universalmente aconsejable la incineración o cremación (12). En segundo lugar, la generalidad de los agentes contaminantes y de las superficies más o menos contaminadas hacen difícil una acción depuradora que no comporte, por

(10) Vid. WARD, B., ob. cit., pág. 110.

(11) Vid. WaRD, B., ob. cit., págs. 104, 105 y 106.

(12) La incineración simple de los plásticos (única forma de destrucción de los mismos) provoca emanaciones de cloro que contaminan la atmósfera. 
otro lado, una actividad de educación, de toma de conciencia de los peligros que los desperdicios, manteniéndose sobre el terreno, pueden producir.

Pero no es ésta la única contaminación de la tierra; en una enumeración simple y ejemplificativa podríamos señalar una degradación de cultivos, consecuencia de un abuso agrícola, una degradación o contaminación producida por edificios y construcciones que afectan o pueden afectar tanto al medio ambiente rural como al medio ambiente urbano, una degradación por el fuego (incendios forestales) y, en fin, una degradación inducida por la de otros elementos (agua y aire).

En definitiva, «la mayor contribución del hombre a la contaminación está teniendo lugar, en forma creciente, sobre la tierra» (13), y no hablamos genéricamente de degradación del medio físico, sino de contaminación propiamente dicha. Los desechos sólidos, los abonos químicos, los herbicidas y plaguicidas, las construcciones, las modificaciones del paisaje, la tala de bosques sin una acción repobladora en paralelo, etc., son aspectos contaminantes del entorno físico. Todas estas acciones provocan, desde el punto de vista de conservación del medio ambiente, un efecto negativo, al atacar valores naturales del entorno físico.

\section{LAS ACCIONES DE DEFENSA DEL MEDIO AMBIENTE}

Esto hace que se piense, desde hace algún tiempo, en la necesidad de actuar en defensa de ese entorno humano recomponiéndolo en la medida en que lo natural (meta última) pueda ser compatible con las necesidades nacidas de la pervivencia de la Humanidad en un estadio de desarrollo adecuado. Con ello se quiere decir que la recomposición del medio es recomposición de un entorno artificial o un medio ambiente modificado que no llega a los peligros o a las degradaciones a que tiende una acción incontrolada.

\section{Sectorialización. Concurrencias competenciales}

Esta acción de defensa del entorno ha pasado, lógicamente, hasta llegar a un nivel de necesidad de intervención de la Administración, por estadios en los que se actuaba una defensa intuitiva o una

(13) Vid. WARD, B., ob. cit., págs. 117 y sigs. 
defensa en tanto en cuanto la acción de los particulares producía perjuicio a otro u otros. Se trataba, entonces, de regular (y aquí terminaba la acción preventiva del Estado) las relaciones entre personas individualmente consideradas. Restos de esta acción podemos ver en las normas contenidas en nuestro Código Civil, cuando trata de la prohibición de construcción, cerca de pared ajena o medianera, de pozos, cloacas, acueductos, hornos, fraguas, chimeneas, establos, depósitos de materias corrosivas, artefactos que se muevan por el vapor o fábricas que por sí mismas o por sus productos sean peligrosas o nocivas (art. 590), o cuando establece la responsabilidad civil por daños en los casos de explosión, emisión de humos o emanaciones de cloacas o depósitos de materias infectantes (art. 1.908).

Un segundo escalón lo forman las acciones adoptadas independientemente por cada parcela de la Administración, en función de la actividad peculiar de cada una de ellas. Se disgrega así la actividad administrativa teniendo en cuenta la distinta naturaleza de los efectos perjudiciales que cada actividad comporta (14) y se llega a una acción protectora, preventiva y represiva múltiple, al incidir varios Departamentos ministeriales o varios Entes administrativos en una misma actividad (15).

La dispersión de competencias desde el punto de vista orgánico y, como consecuencia, la dispersión normativa se ha puesto de relieve por Mola DE Esteban-CERRADa (16), que lleva a cabo una enu-

(14) Vid. Mola de Esteban-Cerrada, F., La defensa del medio humano, Madrid, Servicio Central de Publicaciones del Ministerio de la Vivienda, 1972, págs. 81 y siguientes.

(15) Vid. Prieto Rodrfguez, F., «La actuación administrativa sobre el medio ambiente. Implicaciones jurídicas e institucionales", en Boletín de Información del Ministerio de Obras Públicas, núm. 176, Madrid, agosto 1972, donde se afirma (página 11): «En este sentido, la panorámica española resulta desalentadora. Prácticamente todos los Ministerios tienen atribuida alguna acción sobre el medio ambiente en general e incluso sobre aspectos singulares concretos. Mientras ocho Departamentos ministeriales tengan confiadas atribuciones en materia de contaminación hidráulica, otros tres y los Ayuntamientos puedan y deban reglamentariamente intervenir en materia de contaminación atmosférica y cinco tengan confiadas la vigilancia en la degradación del suelo, aparte de las Corporaciones locales, es y será muy difícil adoptár una política coherente»... "Nuestro ordenamiento juridico ha sido reiteradamente señalado, es sectorial, represivo, anticuado y rígido. Las leyes y disposiciones administrativas contemplan exclusivamente aspectos concretos de la contaminación ambiental, careciendo nuestro acervo legislativo de los códigos medioambientales que han sido promulgados últimamente en diversos países».

La creación del Ministerio de Planificación del Desarrollo, en 1973, con competencias medioambientales, no ha venido a clarificar el panorama.

(16) Ob. cit., págs. 82 a 87. 
meración de todos los Departamentos ministeriales que, de alguna forma, tienen atribuidas competencias en defensa del medio humano y que, desde su perspectiva sectorializada, toman o pueden tomar válidamente decisiones para enfrentarse en el progresivo deterioro de los recursos naturales.

$\mathrm{Si}$, a modo de ejemplo, analizamos someramente la acción administrativa de protección de las aguas, nos encontrariamos con doce Departamentos ministeriales con competencias que concurren en algún aspecto de esa acción sobre ese elemento (17).

Tal pluralidad o concurrencia competencial nace de una diversificación de criterios en el momento de regular la actividad y, consiguientemente, el órgano que ha de llevarla a cabo. "Se ha partido unas veces de la naturaleza de las aguas (marítimas, terrestres, embalsadas); otras de los bienes eventualmente dañados (salud pública, riqueza piscícola, forestal o agrícola, turismo, etc.); otras de la naturaleza de la actividad perjudicial (industrias de diversas clases, detergentes, minas, transportes de hidrocarburos); otras, finalmente, de la localización de la actividad presumiblemente perjudicial (licencia de apertura municipal). $\mathrm{Y}$ es obvio que todos estos aspectos habrán de tenerse en cuenta, pero no aislada, sino - -repetimos- conjunta $o$, al menos, coordinadamente, para poder enfrentarse eficazmente con la contaminación de las aguas» (18).

Si con estas competencias sectorializadas hacemos concurrir las genéricas que derivan de la amplia competencia urbanística (19), tendremos un cuadro verdaderamente confuso de órganos y competencias.

Finalmente, concurren con acciones de defensa del medio (o al menos pueden y deben concurrir) los Entes locales municipales y provinciales. Un somero análisis de la legislación local nos llevaría a conocer la atribución de competencias en relación con la defensa del medio ambiente, que van desde la prevención de los ataques al medio natural (aguas, montes, limpieza, protección y defensa del paisaje, etc.) hasta la acción de defensa del medio cultural (conservación de edificios monumentales artísticos e históricos, creación

(17) Serían: Presidencia del Gobierno, Obras Públicas, Agricultura, Comercio, Marina, Información y Turismo, Gobernación, Industria, Educación y Ciencia, Vivienda, Secretaría General del Movimiento y Planificación y Desarrollo.

(18) Vid. MOLA, ob. cit., pág. 107.

(19) Si consideramos el urbanismo no como algo global, sino como un sector más de actividad, lo que no es desacertado dada la configuración que el urbanismo tiene en nuestro Derecho y su sectorialización administrativa. 
REVL-1975, núm. 188. CORELLA MONEDERO, JOSE-MARIO. FUNCION DE LAS DIPUTACIONES P...

FUNCION DE LAS DIPUTACIONES PROVINCIALES EN LA DEFENSA DEL MEDIO AMBIENTE

de museos) pasando por cualquier aspecto imaginable de actividad que, teniendo por objeto el fomento de los intereses y la satisfacción de las aspiraciones ideales de la comunidad municipal, incidan en el entorno físico $y$, ciertamente, todas las actividades que incidan en ese entorno satisfacen aspiraciones ideales de la comunidad municipal (20).

Por su parte, también las Diputaciones provinciales están legitimadas para acciones que inciden en el medio ambiente de forma muy directa, desde la rectificación de cursos de agua hasta la acción educadora y de conservación del medio cultural (21).

\section{La POSIble INTEGRACIÓN A TRAVÉS dE ENTES DE FINES GENERALES}

Como solución frente a esa sectorialización de que venimos hablando únicamente cabe pensar en una integración de las competencias medioambientales a través de un Ente que pueda aunar todos los criterios sectoriales contemplándolos desde el prisma unitario del territorio, bien sea éste nacional, provincial o municipal.

Entonces, contemplado el problema orgánico de la defensa del medio ambiente con una visión amplia, se nos plantea la disyuntiva de elegir entre la creación de nuevos órganos especializados, con o sin el mantenimiento de competencias en los actualmente existentes, o la reestructuración orgánica y funcional de cuantos Entes tienen hoy competencias medioambientales, aprovechando toda la organización burocrática y de instalaciones ya en funcionamiento que, al parecer, únicamente va a precisar una potenciación (22).

(20) Realmente, en la casi exhaustiva enumeración del artículo 101 de la Ley de Régimen local, y en su cláusula general del apartado $k$ ), se encuentra legitimada cualquier acción municipal de defensa y reacondicionamiento del medio ambiente humano.

(21) Vid. artículo 243 de la Ley de Régimen local, especialmente sus apartados d), $g), k),(), m)$ y $\tilde{n})$.

El artículo 173 del Reglamento de Organización, Funcionamiento y Régimen jurídico de las Corporaciones locales, al regular las atribuciones de las Comisiones informativas de la Diputación, establece como propias de la Comisión de Sanidad, Urbanismo y Vivienda (obligatoria a tenor del artículo 235 de la Ley), las de saneamiento, ordenación urbana y rural y política del suelo y defensa del paisaje.

(22) Vid. Arroyo GonzAlez, M. A., ob. cit., pág. 253, que se formula la pregunta: "¿Creación de nuevos órganos o mantenimiento de los existentes?", aludiendo incluso a una fórmula mixta basada en la realidad de los hechos: «A la vista de este balance, y tal vez para salirse del impasse a que conduce, la mayor parte de los países han adoptado una fórmula mixta consistente en mantener las estruc- 
Al sistema intermedio -creación de nuevos Entes con el mantenimiento de competencias en los actualmente existentes- responde el establecimiento de la Comisión Delegada del Gobierno para el Medio Ambiente, en 13 de abril de 1972, cuya finalidad es la de "coordinar y asegurar la unidad de programación de todas las acciones relativas al medio ambiente y la defensa contra la contaminación...»(23).

Pero esta Comisión, que ha de coordinar a nivel nacional, precisará Entidades de coordinación a niveles inferiores, y más que de coordinación sería necesario hablar de Entes de integración de acciones medioambientales. Y para el cumplimiento de tales objetivos no cabe duda que la existencia de Entes territoriales con generalidad de fines - los Entes locales en general-será de ayuda capital. Ahora bien, se habla, y con razón, de que el Municipio es un ámbito territorial reducido para el ejercicio de algunas funciones que legalmente deben desarrollarse en él, hasta tal punto que algunas de tales acciones han de coordinarse forzosamente con otras similares en Municipios colindantes (24).

Además, si la defensa del medio humano adquiere dimensiones internacionales (25), la ejecución de tales acciones coordinadas no puede dejarse en manos de los Entes inferiores, sino que se hace preciso una coordinación, si no a nivel nacional sí a nivel regional o a nivel supramunicipal.

Parece entonces que las Diputaciones provinciales, en el caso de nuestro país, pueden ser los. Entes idóneos para ejercer esas funciones de puesta en marcha de acciones genéricas y cioncretas de defensa del entorno humano. $Y$ si las configuramos como Administraciones de misión, no cabe duda que son órganos de impulso y promoción, como las ha caracterizado ORTIz Díaz (26).

turas tradicionales, pero creando a la vez un órgano específico (Comisión, Junta, Comité...) de carácter interministerial y dotado, en general, de funciones un tanto vagas. En algunos casos, dichos órganos han constituido una etapa previa para la creación de los actuales Ministerios del Medio Ambiente; en otros, han adquirido carácter permanenten.

Idénticas expresiones emplea ANSÓN, R., ob. cit., págs. 109 y 110.

(23) Artículo 2..$^{\circ}$ del Decreto 888/1972, de 13 de abril.

(24) El artículo 25 de la Ley del Suelo contempla una necesidad de coordinación que resuelve estableciendo una jerarquización de hecho entre varios $\mathrm{Mu}$ nicipios.

(25) “Carta europea del agua», «Declaración europea en materia de conservación de la naturaleza en provecho de las Corporaciones locales», etc.

(26) Vid. ORTIz Dfaz, J., «El desarrollo económico regional, la Administración de misión y las Diputaciones provinciales», en Revista de Administración Pública, número 50, mayo-agosto 1966, págs. 9 y sigs. y en especial págs. 17 y sigs., donde 
Desde otro punto de vista, las circunscripciones territoriales intermedias por su vocación coordinadora vienen siendo consideradas las más aptas para acciones de defensa medioambiental, porque, si bien no tienen acción directa sobre factores de conjunto en la evolución demográfica o del desarrollo económico, «sí disponen de un campo de acción considerable que les abre su cualidad de administradores de vocación general, coordinando la acción de los servicios del Estado y ejerciendo un papel de consejo y de control frente a las colectividades locales»(27).

\section{LA ACCION ADMINISTRATIVA PROVINCIAL EN LA DEFENSA DEL MEDIO AMBIENTE}

Partiendo de una división de las actividades de la Administración pública en actividades de prestación y actividades de limitación (28), las Diputaciones provinciales, en cuanto incide en la defensa del medio ambiente en su circunscripción territorial, pueden actuar en las dos vertientes. Incluso podría hablarse de una tercera forma de actividad, la de coordinación que, según la perspectiva desde la que se contemple se encuadraría en uno $u$ otro tipo de las anteriormente enunciadas, pero que, a efectos expositivos, creemos oportuno independizar.

dice: «Interesa destacar que nuestras Diputaciones provinciales, conservando sus ya tradicionales funciones de "Administración de gestión" -concretadas principal. mente en el sostenimiento y administración de los denominados "establecimientos provinciales"-, se le han ido añadiendo y en la actualidad tienen atribuidos fines y modos de acción administrativa que, por su carácter, determinan que las mismas puedan ser conceptuadas en buena parte como Entes idóneos para cumplir los objetivos y tareas de "Administración de misión"». Y añade, al hablar del Presidente, "que se vislumbra y concibe tal figura como un órgano de "impulso", de "promoción", de "Administración de misión"".

(27) Vid. Perrot, H., ob. cit., pág. 27, donde añade: "C'est pourquoi l'examen de suggestions susceptibles de constituir une sorte de programme d'environnement à l'échelon $d u$ département, par exemple, suppose que l'on brosse un tableau des différents domaines où la conduite de l'action administrative courante simplement sensibilisée par l'attention apportée au milieu de vie peut faire beaucoup» (subrayado nuestro).

"Nul mieux que le corps préfectoral ne peut exercer sur le cadre de vie une action par définition de synthèse et d'ensemble telle que l'implique un aménagement bien conduit".

(28) Vid. Garcfa-Trevijano y Fos, J. A., Tratado de Derecho administrativo, segunda edición, Madrid, Ed. Revista de Derecho Privado, 1968, tomo I, pág. 510, donde afirma: «En el campo de la Administración pública puede hacerse una división de actividades: de limitación y de prestación. Las primeras, como su nombre indica, son aquellas que restringen el ejercicio de los derechos, mientras que las segundas son actividades que otorgan algo a los administrados. Cuando se exigen autoriza- 


\section{ACtividAD DE LimitacióN}

La actividad provincial (o de las Diputaciones provinciales) de limitación se manifiesta en la misma forma que como tal tipo de actividad se desarrolla por cualquier Administración pública. Las licencias o las autorizaciones en general y los medios compulsivos indirectos (multas y sanciones) parece que son las manifestaciones más operantes de esta actividad limitativa.

$\mathrm{Si}$ analizamos las normas vigentes, tanto las licencias como las multas son medios que pueden usar las Diputaciones provinciales en su actividad de limitación. En efecto, cuando el Reglamento de Servicios de las Corporaciones locales de 17 de junio de 1955 regula en su artículo $5 .^{\circ}$ la intervención de las Corporaciones locales en la actividad de sus administrados, y cuando en el $80^{\circ}$ y en el $9 .^{\circ}$ establece la posibilidad de obligar a la obtención de previa licencia y señala el trámite general para ello respectivamente, no está limitando su normativa a los Ayuntamientos, sino que el sujeto pasivo de la norma son todas las Corporaciones locales, tanto las municipales como las provinciales.

Cierto que la gama de posibilidades de acción administrativa de los Ayuntamientos es superior a la de las Diputaciones provinciales, pero ello no quiere decir que haya que negar a éstas la posibilidad de una actividad de limitación a través de este especial tipo de autorizaciones (29). Así, por ejemplo, el artículo 604 de la Ley de Régimen local no señala como ingresos por derechos o tasas los derivados de la expedición de licencias en concreto (30), pero la facultad de expedirlas no cabe duda que puede pensarse contemplando el problema desde una perspectiva legal, en cuanto que los artículos $5 .^{\circ}, 8 .^{\circ}$ y $9 .^{\circ}$ del Reglamento de Servicios son de carácter general y en cuanto que para las licencias urbanísticas (31)

ciones previas para desarrollar una actividad, nos movemos en el campo de las limitaciones, pero cuando la Administración explota un hospital o presta un servicio ferroviario o de correos y telecomunicación, está prestandos.

(29) Vid. Garrido Falla, F., Tratado de Derecho administrativo, Madrid, I. E. P., 1970, 5.2 ed., vol. I, págs. 451 y sigs. y en especial 458 a 462.

(30) Cabe deducirlo de las fórmulas generales de los apartados a) y f) del número 2 de dicho artículo 604 .

(31) Sobre el concepto y contenido de las licencias urbanísticas, vid. González PEREZ, J., "Las licencias urbanísticas» en Revista de Estudios DE LA VIDA LoCal, número 154, julio-agosto 1967, págs. 499 y sigs., y Vallina Velarde, J. L., "Licencias urbanísticas», en Revista de Derecho Administrativo y Fiscal, núm. 34, La Coruña, 1973, págs. 5 y sigs. 
la Ley del Suelo faculta a las Diputaciones a subrogarse en las competencias municipales de este orden (32).

Desde la perspectiva sancionadora falta una construcción legal y doctrinal respecto a las facultades de este orden de las Diputaciones provinciales, o de sus Presidentes. Ciertamente, el artículo 602 de la Ley de Régimen local señala dentro de las exacciones provinciales, en su apartado $d$ ) del párrafo 1 , «multas en la cuantía y en los casos que autorizan las leyes", pero esa autorización legal únicamente aparece clara en lo que hace referencia a las infracciones fiscales y a las multas por ocultación o defraudación que pudieran imponerse. Ahora bien, y volviendo al ámbito urbanístico, cuando las Diputaciones se subrogan en las facultades de este tipo de los Ayuntamientos, la facultad de imponer sanciones (multas por infracciones urbanísticas o decisiones de demoler) deben ser atribuidaș al Presidente de la Corporación provincial o a ésta, según los casos.

\section{ACTIVIDAD DE PRESTACIÓN}

Habría que distinguir dos aspectos de manifestación de este tipo de actividad. El primero de ellos sería una prestación indirecta a través de medidas de fomento para que actuaran en el sentido querido por la Administración provincial, otros Entes o los particulares. El segundo tipo de actividad sería el de prestación propiamente dicha, ejecutando obras, prestando servicios $u$ ordenando actividades.

\section{A) Actividad de fomento}

La actividad de fomento, como "técnica operativa de la Administración», puede dirigirse tanto a los particulares como a otros Entes públicos (33). Claro es, a este respecto, lo preceptuado en el

(32) Véanse los artículos $5 .^{\circ}, 4$, y 205 de la Ley del Suelo, planteándose respecto a este último si la alusión que hace a la autorización del Ministerio de la Gobernación debe entenderse referida al de la Vivienda, una vez creado éste en 1957, o es una autorización no transferida, y el órgano autorizante, como órgano general de tutela, debe seguir siendo el Ministerio de la Gobernación.

(33) Vid. Garrido Falla, F., ob. cit., vol. II, 4.' ed., Madrid, 1971, págs. 303 a 306, donde define la actividad de fomento como «aquella actividad administrativa que se dirige a satisfacer indirectamente ciertas necesidades consideradas de ca- 
artículo 23, 1, del Reglamento de Servicio, al establecer que «las Corporaciones locales podrán conceder subvenciones a entidades, organismos o particulares cuyos servicios o actividades complementen o suplan los atribuidos a la competencia local...».

Como técnica operativa de fomento, la Ley de Régimen local primero y el Reglamento de Servicios de las Corporaciones locales después, van a regular la cooperación de las Diputaciones provinciales a la efectividad de los servicios municipales, aplicando (artículo 255, 1, de la Ley de Régimen local) los medios económicos que específicamente se señalan, la ayuda financiera que a través de ellas conceda el Estado y las subvenciones de cualquier otra procedencia.

Si esta actividad de cooperación se entiende como actividad de fomento no cabe duda que, por su medio, y dada. la obligatoriedad de su prestación, las Diputaciones provinciales van a poder participar en todas las competencias municipales de protección medioambiental. Entonces el juicio de valor que puedan forma estos Entes locales intermedios al confeccionar el Plan provincial de cooperación, prestando mayor o menor atención a los servicios de protección ambiental, va a calificar una actividad provincial como acción de protección ambiental, aunque sea por vías indirectas.

Si en la amplia gama de actos, los que entendemos defensores del medio ambiente, las Diputaciones provinciales pueden tener una opción política en cuanto a la concreta dirección de sus inversiones de cooperación, no hay lugar a dudas que su influencia en la defensa del medio ambiente provincial puede ser eficaz. Así, en la implantación de abastecimientos de agua a poblaciones, en las obras para la depuración de las residuales, en la defensa contra incendios (34) en el establecimiento de estaciones de tratamiento $\mathbf{v}$ destrucción de residuos sólidos, e incluso al ordenar los usos del territorio provincial (35) pueden actuar de manera muy directa en

rácter público protegiendo o promoviendo, sin emplear la coacción, las actividades de los particulares o de otros Entes públicos que directamente las satisfacen» (subrayado nuestro).

Pellisé PRATS, B., distingue entre medidas de fomento positivas y negativas. En cuanto al sujeto pasivo de la actividad de fomento, únicamente habla de los administrados. Cfr. voz «Fomento" en Nueva Enciclopedia Juridica, Seix, t. X, Barcelona, 1960, página 5 especialmente.

(34) La Ley de Bases del Estatuto del Régimen local en su base 39.6 establece como competencia de las Diputaciones provinciales los servicios de lucha contra el fuego.

(35) Artículo 8. de la Ley del Suelo. 
la prevención de degradaciones y en la mejora del medio ambiente dentro de su ámbito jurisdiccional.

Ciertamente, estas posibilidades no son nuevas, y si las Diputaciones provinciales no han planteado su actividad desde la perspectiva medio-ambiental, habrá que hacerlas participar en la culpa, por omisión, que de alguna forma nos salpica a todos, de la actual situación del entorno humano.

$\mathrm{Y}$ junto a esta actividad de cooperación a la efectividad de los servicios municipales, las Diputaciones, con las medidas de fomento dirigidas a otros organismos $\mathrm{y}$ particulares $\mathrm{y}$, fundamentalmente, a través de las subvenciones (36), pueden llegar, siempre que tengan un plan preconcebido y correctamente orientado, a conseguir apreciables resultados en la defensa del medio, no sólo en el ámbito rural, sino incluso en los núcleos de población más o menos densos, si sabe ejercitar su labor coordinadora.

\section{B) Actividad de prestación propiamente dicha}

Con ser importantes los medios indirectos de acción prestadora, a través de los cuales cabe una incidencia en competencias no exclusivamente propias, no debe olvidarse el análisis de las posibles actividades de prestación en el orden medioambiental a través de la ordenación, de la ejecución de obras y de la prestación directa de servicios.

La ordenación del territorio provincial, ordenación urbanística (37), es o deber ser al mismo tiempo ordenación del medio fí-

(36) Con las limitaciones que legalmente hay establecidas para controlar el correcto ejercicio de la facultad de subvencionar.

(37) Cabría distinguir, y ya en alguna ocasión, con motivo de clases impartidas en el Instituto de Estudios de Administración Local, lo planteaba como tema de discusión, entre ordenación urbana y ordenación urbanística. La primera está referida a los núcleos de población y a su entorno inmediato, pretendiendo la mejora de las condiciones de vida de una comunidad humana agrupada. La ordenación urbanística es ordenación integral de un territorio en función de los núclcos de población, pero no se reduce a la regulación de los asentamientos humanos, sino a una integral regulación de los usos del suelo. En este sentido, nuestra Ley del Suelo de 1956 tiene regulaciones de carácter urbanístico (del territorio en función de la ciudad) y no meramente urbano. Y de ahí que pueda considerarse como una Ley de ordenación del territorio en la que se contienen normas que facultan a esa ordenación territorial sin necesidad de buscar una ley especialmente dirigida a ello. El contenido del Plan provincial, hoy de los Planes Directores Territoriales de Coordinación, e incluso el del Plan general, es un contenido que puede enlazar muy de cerca con la orientación integral del territorio, mucho más incluso que con la mera ordenación de la ciudad. 
sico provincial (38). El artículo $8^{\circ}$ de la Ley del Suelo de 1956 facultaba para ello, hablando que comprendería, entre otras cosas, la "ordenación de la estructura urbanística de la Provincia», y no parece aventurado afirmar que cuando hablaba de estructura urbanística se estaba refiriendo a la estructura del territorio provincial en función de sus núcleos de población. No se ordena sólo la estructura urbana, sino el total ámbito territorial provincial, en tanto en cuanto sobre él existen unos asentamientos humanos. Hoy el artículo $8 .^{\circ}$ bis de la Ley $19 / 75$, de 2 de mayo, vuelve a atribuir a las Diputaciones provinciales competencias ordenadoras a través de los Planes Directores Territoriales de Coordinación.

Era ésta una forma de planificación provincial, planificación físíca que, si estaba correctamente adoptada, debía contemplar y contener una planificación de obras (en el propio ámbito territorial) y una planificación de servicios.

La realidad demuestra, sin embargo, que tal tipo de planificación (que de alguna forma pudiéramos considerar planificación integral) tuvo escaso éxito en el ámbito nacional. Quizá se debió a la raquítica regulación de los Planes provinciales en la Ley del Suelo, para los que había que inventar una gran parte de su contenido; puede que se considerase el urbanismo como algo exclusivamente municipal y estatal; quizá, por fin, la incidencia de la Administración del Estado en el ámbito provincial a través de los Planes Provinciales de Obras y Servicios (39) hiciera perder la perspectiva de esa planificación integradora. De cualquier forma no cabe duda de que, a los diecinueve años de vigencia de la Ley del Suelo, únicamente tres Planes provinciales de carácter territorial existen: Baleares, Guipúzcoa y Barcelona.

Así las cosas, la conclusión lógica ha de ser acusatoria para las Diputaciones provinciales desde el punto de vista de las posibilidades que en su manos tienen y no ejercen para una acción real y efectiva en el ámbito de planificación territorial, que es al mismo tiempo y muy directamente, ámbito de la defensa medioambiental.

Junto a esta acción prestadora, concretada en una normativa de ordenación territorial, la actividad de prestación de las Diputacio-

(38) Sebastián MARTf́N-Retorilllo, en una ponencia expuesta ante el Seminario de la O. C. D. E. sobre «Planificación y Gestión Urbanísticas, celebrado en Madrid del 7 al 10 de abril de 1975, se manifestaba también -al menos así lo entendíen el sentido de que en la Ley del Suelo había contenido suficiente para poder llegar a unos Planes de ordenación del territorio.

(39) Los llevados a cabo por la Comisión Provincial de Servicios Técnicos. 
nes provinciales en la ejecución de obras y prestación de servicios también incide en la degradación o en la recomposición del medio. Ahora bien, en este grupo de actividades las más de las veces no se contempla el problema integral del entorno, sino únicamente necesidades provinciales que pueden traducirse en apreciaciones económicas. La falta de criterios medioambientales (criterios definidos, analizados, aprobados y sobrepuestos a toda actividad de prestación) se sustituye por unos criterios a corto plazo en los que prima la ventaja inmediata, que, generalmente, suele ser de rendimientos económicos próximos en el tiempo, bien para la propia Administración (provincial o municipal), bien para la generalidad de los habitantes del territorio provincial.

La competencia de las Diputaciones provinciales en este aspecto prestador se contiene en la propia Ley de Régimen local, y si analizamos el artículo 243, rápidamente deduciremos la conclusión de que una gran parte de esas competencias inciden de manera muy directa en el entorno físico. Si esa incidencia es degradadora o recompensadora del medio, únicamente se sabe cuando los órganos de gobierno provinciales han tomado conciencia de la defensa del entorno; en caso contrario, la incidencia de la obra o servicio, una vez ejecutada o prestado, respectivamente, nos hará conocer su carácter.

El análisis de ese artículo 243 de la Ley de Régimen local, sin perjuicio de la cláusula general contenida en el artículo precedente, nos lleva a la siguiente clasificación de las competencias de la Diputación, con posible incidencia medioambiental:

a) Es incuestionable que la ejecución de cualquier obra de nueva planta o la instalación de ciertos servicios inciden directamente en el paisaje, ya sea urbano o rural. En consecuencia, toda actividad provincial podría y debería contemplarse desde este prisma. El apartado a) del artículo 243, cuando atribuye como competencia a las Diputaciones la construcción y conservación de caminos y vías locales y comarcales, está facultándolas para que, a través de esa construcción y a través de su actividad de conservación, puedan incidir con mayor o menor intensidad en una degradación o en un mejoramiento del paisaje. La construcción y explotación de ferrocarriles, tranvías y trolebuses (apartado $b$ ) del propio artículo) puede provocar también esa incidencia, fundamentalmente por la necesidad de elementos fijos sobre el terreno. 
Incluso la construcción y conservación de caminos puede producir esa incidencia de degradación cuando, desde algunos puntos de vista, se piensa que los caminos asfaltados inciden en el paisaje, produciendo un perjuicio desde una doble perspectiva: la de incidencia de un elemento artificial (el firme asfáltico); y la facilidad que supone para el acceso con vehículos de motor, produciendo desequilibrios más o menos fuertes debidos a la presencia del vehículo, a la emisión de humos y a la producción de ruidos (40).

Junto a estas acciones, de indudable repercusión en el paisaje rural, la conservación del paisaje urbano está presente en las competencias de las Diputaciones, cuando el apartado $m$ ) del artículo 243 de la Ley de Régimen local les confiere las de conservación de monumentos y de lugares artísticos e históricos.

b) Esas acciones de incidencia en el paisaje deben coordinarse con las que la propia Diputación deberá ejercitar para la conservación de la Naturaleza, de tal forma que no aparezcan como incompatibles unas y otras.

Las competencias de los apartados d), e) y $g$ ) del artículo 243 son manifestaciones claras de esa acción de defensa, aunque, como es lógico, se manifiestan como posibilidad de actuación sectorial hacia determinados aspectos de conservación, y no integral con un

(40) Vid. WARD, B., ob. cit., págs. 153 y 154, donde afirma: a... Algunas veces, en su deseo de mejorar el acceso de los paseantes domingueros a las bellezas no urbanas, las autoridades locales echan a perder lo que la gente viene a ver, ampliando los caminos, suavizando las curvas, derribando árboles e incluso mutilan. do, con la mejor intención, la belleza silvestre de la vegetación de la vera de los caminos y los setos vivos, para establecer una uniforme pradera suburbana".

«En las áreas rurales distantes surge un problema más. Si todo el mundo concurre al mismo lugar hermoso, ¿qué belleza quedará para ver? Una respuesta parcial se está aplicando en Gran Bretaña. Se están estableciendo lugares de estacionamiento, ocultos por cortinas de árboles, a lo largo de las colinas Pennine, de los cuales parten senderos rurales y caminos de herradura. De ahí en adelante sólo se permite el acceso a pie...».

Por su parte, PERROT, H., «Environnement...», cit., afirma: «Asphalter les chemins forestiers par exemple ne s'impos pas toujours, bien au contraire» (página 36).

Y, finalmente, VILmoRIN, J. B., en Le rôle des pouvoirs locaux..., cit., establece que «D'une façon générale, le trace d'une route nouvelle doit être étudié en collaboration avec des biologistes et des spécialistes de la protection de la nature et des sites. Une route mal dessinée peut irrémédiablement détruire l'harmonie d'un paysage. Il est, le plus souvent, absurde de couper une forêt en dense, alors qu'il serait tout aussi simple de la contourners.

«Les routes de bord de mer ou de corniche rendent des sites inutilisables pour les campeurs et les touristes en isolant la côte de l'arrière-pays. On leur préférera des voies de circulation intérieures et dissimulées en utilisant le milieu naturel. Des voies secondaires, partant de la route intérieure, permettront, d'atteindre la côte où elles se termineront par une aire de stationnement pour éviter que les automobilistes n'arrêtent leur véhicle au hasard, dans le milieu naturel». 
análisis del entorno natural en su conjunto, que sin duda llevaría a un ejercicio más racional de esas competencias, a veces, aparentemente incompatibles.

La defensa de los bosques y de las aguas (apartados $g$ ) y $d$ ), respectivamente) son manifestaciones concretas de esa sectorialización a que antes se aludía.

c) La educación ambiental también tiene su puesto en las competencias de la Provincia como Entidad local. Cuando se habla de «establecimientos de granjas y campos de experimentación agrícola» (en el apartado $e$ ) o de "difusión de la cultura» (apartado $k$ ) puede pensarse que una acción educativa desde la perspectiva medioambiental es posible.

\section{C) Actividad de coordinación}

Cuando más arriba se aludía a la posible función urbanística de las Diputaciones provinciales y se estimaba como acción de prestación la redacción y aprobación de los Planes provinciales, y hoy de los Planes Directores Territoriales de Coordinación, quedaba por analizar lo que tales Planes podían representar en la acción coordinadora, que en la defensa del entorno humano es propia de tales Entes. Los Planes de Ordenación del Territorio Provincial, tal como se les contemplaba en el artículo $8 .^{\circ}$ de la Ley del Suelo de 12 de mayo de 1956, eran realmente Planes coordinadores de la actividad urbanística de los Municipios de la Provincia. Concretamente el apartado $d$ ) de dicho artículo obligaba a que tales ordenaciones provinciales contemplaran y resolvieran la coordinación del Plan provincial con los Planes generales de la capital y de las poblaciones que tuvieran relevantes problemas de este orden; y esta coordinación se planteaba también cuando el Plan provincial debía ordenar la estructura urbanística de la Provincia (apartado $c$ ). En el mismo orden de cosas puede pensarse en el futuro cuando el Plan provincial es sustituido por un Plan Director Territorial de Coordinación, cuya redacción se atribuye, en ciertos supuestos, a las Diputaciones provinciales en la Ley de Reforma de la Ley del Suelo de 2 de mayo de 1975 (41).

(41) El artículo $8 .^{\circ}$ bis establece que «las Diputaciones provinciales y Cabildos insulares podrán redactar, por propia iniciativa o a petición de los Ayuntamientos respectivos, Planes Directores Territoriales de Coordinación cuando el ámbito territorial de los mismos afecte a la totalidad o parte del respectivo territorio provincial...». 
Junto a estos Planes territoriales, que deberían ser integradores de todas las actividades que tengan por marco físico el territorio provincial, en la función o actividad coordinadora nos encontramos también con los Planes provinciales de cooperación, que deben, aunque a veces no lo hagan, responder a un criterio tendente a aunar la acción concreta de los Municipios desde la perspectiva medioambiental, estableciendo una jerarquización de dos servicios municipales merecedores de la cooperación provincial y determinando cómo pueden coordinarse unos con otros de manera que la inversión económica sea más eficaz y la incidencia en el medio menos perjudicial.

La Ley de Bases del Estatuto del Régimen local señala en su base 17 que "corresponde a las Diputaciones provinciales intervenir, de manera directa y en colaboración con los organismos del Estado, en las materias relativas a la planificación territorial provincial. También elaborarán y ejecutarán el Plan de Obras y Servicios de la Provincia». Ese Plan de Obras y Servicios «comprenderá los propios de la Diputación, los correspondientes a los Ayuntamientos financiados con ayuda estatal o provincial que no se ejecuten por la Administración central y los de competencia estatal cuya realización esté encomendada a la Diputación... El Plan será elaborado por la Diputación... Su ejecución corresponderá a la Diputación» (base 46).

Aparece aquí una función coordinadora claramente manifestada para el ámbito provincial, función que compete a la Diputación, sin perjuicio de la coordinación, que en la propia base $4 \dot{6}$ se predica como atribución de la Comisión Provincial de Servicios Técnicos (42).

Además, la función coordinadora de las Diputaciones provinciales podrá verse ampliada con la aplicación de los medios, que la base 47 prevé, de colaboración de las Entidades locales a la realización de servicios de la Administración del Estado, aunque tal colaboración tenga que establecerse en algunos casos previa petición

(42) El número 3 de la base 46 dice textualmente: «La Comisión Provincial de Servicios Técnicos será un órgano de coordinación de las Delegaciones de la Administración del Estado en la Provincia y servirá de enlace entre aquéllas y los Entes locales de la misma, sin perjuicio de las funciones atribuidas por esta Ley a las Diputaciones. 
de las propias Entidades locales, en este caso las provinciales, o participando en alguna de las modalidades de gestión que establece el número 4 de la base citada (43).

\section{LA PLANIFICACION TERRITORIAL Y SU REPERCUSION EN LA DEFENSA DEL MEDIO AMBIENTE}

\section{LA ORDENACIÓN DEL MEDIO COMO RACIONALIZACIÓN DEL ENTORNO H UMANO}

Tanto el Plan provincial, regulado en el artículo $8 .^{\circ}$ de la Ley del Suelo de 1956, como los Planes Directores Territoriales de Coordinación, tienen una característica común: son Planes de Ordenación del Territorio y no simplemente Planes de Ordenación Urbana.

Desde esta perspectiva, estos Planes de coordinación cumplen las siguientes funciones:

1..$^{\mathrm{a}}$ Distribución de los usos en el suelo afectado y establecimiento de limitaciones.

El apartado a) del número 2 del artículo $8 .^{\circ}$ de la Ley de Reforma de la Ley del Suelo (44) establece como primera determinación de los Planes Directores Territoriales de Coordinación «el esquema para la distribución geográfica de los usos y actividades a que debe destinarse prioritariamente el suelo afectado", y el apartado $b$ ) señala cuáles sean las limitaciones de uso por exigencias de la defensa nacional o por otras razones de interés público. Nos encontramos así con una primera función de coordinación urbanística que incide muy de cerca en la defensa del entorno humano: el suelo se utilizará únicamente según los usos previstos en el Plan Director Territorial de Coordinación, debiendo acomodarse a las directrices que en él se marquen el resto de los Planes (artículo 9., número 2). Partiendo de una necesaria información previa derivada del estudio de los suelos en el ámbito territorial del Plan de Coordinación, si tales estudios son correctos y si se tienen en cuenta normas elementales de conservación y protección según determinadas características, sin duda se está sentando el primer criterio protector en cuanto que los usos (rústicos o urbanos, residenciales o industriales) comportan una incidencia en el entorno natural, in-

(43) "Concesión, gestión interesada, concierto y consorcio o sociedad mixta».

(44) Ley 19/1975, de 2 de mayo (Boletín Oficial del Estado del 5). 
cidencia que puede ir desde una compatibilización entre la protección a la Naturaleza y el desarrollo hasta los extremos opuestos de dar primacía a uno de los dos términos (el desarrollo prima sobre el medio, o contrariamente, la defensa del medio entorpece y limita el desarrollo).

Por otra parte, las limitaciones en los usos permitidos, por razones de interés público, pueden llevar a una concepción limitativa en la que el interés público coincida con la defensa del entorno en áreas determinadas. Tales limitaciones de usos pueden afectar no solamente a los asentamientos humanos y a los industriales, sino a las consecuencias o secuelas que en función de ellos se producen en la Naturaleza (conducciones de agua, de saneamiento, de electricidad, etc.), incluso en parajes alejados de los propios asentamientos.

\section{2. ${ }^{a} \quad$ Protección ambiental.}

Si al determinar los usos del suelo, teniendo en cuenta la incidencia que pueden provocar en el entorno, se puede llevar a cabo una muy directa función de defensa del medio ambiente natural o artificial, cuando el apartado $c$ ) del artículo 8. ma de la Ley del Suelo establece en concreto que los Planes Directores.Territoriales de Coordinación determinarán «las medidas de protección a adoptar en orden a la conservación del suelo, de los demás recursos naturales y a la defensa, mejora, desarrollo o renovación del medio ambiente natural y del patrimonio históricoartístico», la perspectiva integral de defensa aparece en toda su amplitud. Los Planes Directores Territoriales de Coordinación son planes de ordenación territorial con una amplia vocación de defensa del entorno natural y del entorno cultural.

Tal vocación venía siendo consustancial con los Planes provinciales del artículo $8 .^{\circ}$ de la Ley de 1956, que debían contener normas para la defensa de la Naturaleza, del paisaje, del medio rural y del patrimonio artístico de las poblaciones.

En consecuencia, desde 1956, cuando menos, las Provincias, como Entidades locales, han tenido posibilidades, no aprovechadas, de incidir de manera muy directa en la ordenación, regulación y defensa del medio ambiente. $\mathrm{Y}$ no solamente con acciones concretas en determinados sectores y para determinados elementos susceptibles de degradación, sino integralmente a través de la ordenación de usos del territorio provincial. 
En esta función, que pudieron desempeñar los Planes provinciales y que ha de atribuirse a los Planes Directores Territoriales de Coordinación, está contenida la afirmación de que la defensa del medio ambiente es, de alguna forma, un urbanismo (45), porque si éste lo que pretende conseguir es el mejoramiento del cuadro de vida en que el hombre se desenvuelve, en ese cuadro de vida debe comprenderse todo el ámbito natural, el ámbito cultural y el ámbito económico. Unicamente conjugándolos se podrá conseguir una ordenación medioambiental en la que lo urbano no sea nocivo.

\section{3..$^{a}$ Señalamiento y localización de infraestructuras.}

Podría considerarse este grupo de determinaciones de los Planes Directores Territoriales de Coordinación como una manifestación concreta de los usos del suelo. Las infraestructuras relativas a comunicaciones, abastecimiento de agua, saneamiento, suministro de energía y otras análogas de que habla el apartado $d$ ) del artículo $8 .^{\circ}$ de la Ley 19/75 de Reforma de la Ley del Suelo, comporta un destino del suelo, del vuelo y del subsuelo que ha de incidir en los usos del primero o que es consecuencia directa de

(45) Vid. Perrot, H., ob. cit., pág. 20, donde afirma: aLa dimensión espacial del entorno (medio ambiente) es de alguna forma una ordenación, un urbanismo, de tal modo que la salvaguarda de los equilibrios naturales y la utilización de los espacios que se enrarecen concurren a la calidad de la vidan.

«Su dimensión temporal consiste en hacer compatible un cierto desarrollo económico con la conservación del medio. Estas dos dimensiones se vuelven a unir sobre el terreno, donde, desarrollando concepciones de ordenación y de urbanismo, se trata de localizar las diversas actividades humanas, de manera tal que el cuadro de vida permita a aquellos para los que está concebido vivir allí de manera convenienten.

Y añade (pág. 27): «Es, pues, en el estadio de la ordenación -es decir, de la localización de equipamientos y actividades, según los destinos a atribuir a los suelos, siguiendo su vocación y las necesidades-donde la preocupación por el medio ambiente debe intervenir en primer términon.

Vid. también GARCfa DE PABLOS, R., "La protección del paisaje y la conservación de la Naturaleza por medio de la ordenación del territorio y de la planificación urbanísticas, en Ciudad y Territorio, núm. 2/71, abril-junio 1971, págs. 6 a 12 . En la página 9 afirma: «El concepto dominante de las tres reuniones a que aludo (Conferencia de Ministros responsables de la defensa de conjuntos histórico-artísticos, de Bruselas, en noviembre de 1969; Conferencia sobre la conservación de la Naturaleza, de Strasburgo, en febrero de 1970, y Conferencia europea de Ministros responsables para la ordenación del territorio, celebrada en Bonn en septiembre de 1970), ha sido el de señalar que la conservación de la Naturaleza debe ser enfocada en una amplia política de ordenación del territorio, conseguida a través de los correspondientes planeamientos urbanísticos y en todos los niveles: continental, nacional, regional, comarcal y localn.

Y añade más adelante (pág. 12): «Hemos sido, señores, técnicos de "casa de socorro", $y$, en consecuencia, la medicación que hemos suministrado al territorio enfermo ha sido de emergencia y muy pocas veces se ha llegado a tiempo de actuar sobre un suelo no invadido para realizar una planificación de defensa de los valores naturales y una reglamentación exigente de la protección de la Naturaleza». 
esos usos. Parece lógico entonces que no deban separarse los tres grupos de determinaciones que hemos formado, sino que, por el contrario, el Plan contemple los usos, las medidas de protección y las infraestructuras desde una perspectiva común. Y aquí está la decisión política jugando su papel preponderante. En definitiva, se está tratando de ordenar el desarrollo y de compatibilizarlo con las acciones de defensa del entorno humano, haciéndose necesario encontrar el equilibrio entre dos fines aparentemente contrapuestos. Los técnicos pueden presentar las soluciones, unas económicamente más ventajosas que otras, pero es a los políticos a quienes corresponde realizar la opción, teniendo en cuenta la existencia de acciones cuyá evaluación económica escapa del campo de los números para entrar en el de las apreciaciones subjetivas.

En consecuencia, no es aventurado afirmar que los Planes Directores Territoriales de Coordinación, y en lo que afecta a nuestro estudio, cuando tienen ámbito provincial o infraprovincial, pero supramunicipal (los Planes Directores de ámbito comarcal), tienden a una ordenación del medio ambiente, en el aspecto amplio que al comienzo de este estudio se establecía, con la finalidad de racionalizar el entorno humano. $Y$ esta racionalización se manifiesta en aspectos urbanos y de infraestructuras urbanísticas y en aspectos no urbanos que afectan al territorio en general, incluso al que no debe llegar de ninguna forma (46) el desarrollo urbano. Se trata de establecer unas normas para el uso racional del entorno en el que el hombre se desenvuelve, organizándolo, desarrollándolo, preservándolo y protegiéndolo en función del hombre mismo, y no sólo atendiendo a sus necesidades físicas, sino también a sus necesidades espirituales, especialmente a las necesidades, a veces no sentidas por muchos, de orden cultural y estético.

El problema que va a plantearse, como en toda ordenación territorial, es el de por qué se opta por una solución concreta, que comporta una adopción de postura en la disyuntiva medio ambiente versus desarrollo, y no por otra que puede comportar, según criterios, mayores ventajas. Se incide aquí, de nuevo, en el aspecto político de la cuestión: la opción es (tiene que ser siempre) una opción adoptada según los criterios determinantes de quienes ostentan el poder. Si para adoptar la decisión, la etapa previa de la fijación y señalamiento de las metas y objetivos que se quieren

(46) Por sus características físicas, que es necesario proteger (ecológicas, paisajísticas, agrícolas, forestales, etc.). 
alcanzar no ha sido correctamente formulada, la decisión final resultará incorrecta. De ahí que se tenga que propugnar una participación ampliamente democrática en algún momento del procedimiento de racionalización de ese espacio social, y fundamental. mente participando en el órgano decisor para conjugar el mayor número de criterios, evaluando todos y cada uno de ellos en función del bien común.

Por su parte, los Planes generales, tal como se configuran en el artículo 9. ter de la Ley de Reforma de la Ley del Suelo (Ley 19/75, de 2 de mayo), tienden hacia una ordenación medioambiental, tanto en el suelo urbano como en el urbanizable o no urbanizable.

En términos generales, el apartado $d$ ) del número 1 del citado artículo $90^{\circ}$ ter señala, entre las determinaciones que han de contener los Planes generales, las «medidas para la protección del medio ambiente, conservación de la Naturaleza y defensa del paisaje, elementos naturales y conjuntos urbanos e histórico-artísticos, de conformidad, en su caso, con la legislación específica que sea de aplicación en cada supuesto». Así, el Plan general se configura como concreción, en el ámbito territorial a que se refiere, de todas las acciones sectorializadas que puedan incidir en la defensa o protección de alguno de los elementos del medio ambiente natural o del medio ambiente artificial comprendidos en el espacio físico que regula, debiendo conseguir una coordinación de todas las acciones, contempladas desde un punto de vista integral.

Cuando más adelante, el propio artículo, concreta esas determinaciones de carácter general, obliga a que en los Planes se contengan, en suelo urbano, una asignación de usos, una delimitación de zonas verdes y espacios libres, una reglamentación pormenorizada de los usos, condiciones higiénico-sanitarias de las construcciones y características estéticas de la ordenación, de la edificación $y$ de su entorno, criterios de defensa o de recomposición de un medio ambiente urbano que conviene destacar.

En el suelo urbanizable, por su parte, la fijación de usos globales supone una precisión que incide muy de cerca en la protección ambiental.

Y, finalmente, para el suelo no urbanizable, el Plan general «establecerá las medidas y condiciones que sean precisas para la conservación y protección de todos y cada uno de sus elementos naturales, bien seá suelo, flora, fauna o paisaje, a fin de evitar su degradación.... 
Se ve claramente cómo la preocupación por la defensa del entorno humano no es una preocupación exclusivamente referida a la ciudad, sino a todo un ámbito territorial más amplio (el total ámbito municipal o el de varios Municipios) que comprende lo urbano, lo que puede llegar a ser urbano y lo que de ninguna forma puede urbanizarse, es decir, lo que más expresivamente el proyecto de ley llamaba suelo rústico protegido y que, con un cambio de perspectiva en su regulación, las Cortes han denominado suelo no urbanizable (47).

Tenemos entonces que Planes Directores Territoriales de Coordinación y Planes generales pueden y deben configurarse como planeamientos de defensa del entorno humano (natural y artificial), y a las Diputaciones provinciales les afecta muy directamente ambos tipos de planificación. El primer tipo, porque los Planes Directores Territoriales de Coordinación pueden ser redactados por ellas cuando tengan ámbito provincial (artículo $80^{\circ}$ bis, 1), y el segundo, en cuanto que la competencia de las Diputaciones es exclusiva para formar Planes generales que afecten a más de un término municipal (artículo 9. bis, 4). Así, la competencia en la defensa y protección del entorno, antes vaga, ahora se concreta en favor de las Diputaciones que adquieren una amplia perspectiva de acción.

\section{LAS LICENCIAS COMO CONTROL DE PROTECCION AMBIENTAL}

Si las licencias como control de la actividad de los particulares se refieren tanto a las construcciones como a los usos del suelo (artículo 165 en la redacción dada por la Ley 19/75) y, aunque el artículo 166, así como la Exposición de Motivos de la Ley de Reforma, declaran que el otorgamiento de aquéllas corresponde al Ayuntamiento, la propia salvedad de ese artículo 166 («salvo en los casos previstos por la presente Ley") da ocasión para intervenir en esta forma de control previo, de constatación anterior a los usos del suelo, a las Diputaciones provinciales, cuando hagan uso de la

(47) La expresión asuelo rústico protegido» hace referencia a características inmanentes de ese suelo, mientras que la expresión asuelo no urbanizable» varía el enfoque y unifica la clasificación de todo el suelo de un término municipal (o de varios), contemplándola desde la posibilidad o no de incorporarse al desarrollo urbano. Ahora se clasifica el suelo en virtud de circunstancias trascendentales; antes se calificaba el suelo en función de circunstancias inmanentes. 
facultad (desde luego reglada) que les confiere el artículo 205 de la Ley de asumir las obligaciones urbanísticas de los Ayuntamientos (48).

Porque pensamos que esta asunción de obligaciones por parte de las Diputaciones provinciales comporta el derecho de intervención en la actividad de los administrados a través de la concesión de las licencias (49) por transferencia de toda la actividad urbanística municipal.

No cabe duda que la Ley 19/75 de Reforma de la Ley del Suelo ha potenciado en toda su regulación de la planificación urbanística la perspectiva medioambiental. La Exposición de Motivos ya advierte que los Planes Directores Territoriales de Coordinación tienen "como misión fundamental la de señalar las grandes directrices que han de orientar y coordinar la ordenación urbanística (50) del territorio dentro de los Planes de Desarrollo y con la adecuada atención a los problemas del medio ambiente». Y el artículo 9., 1, de la Ley de 1975, después de establecer que los

(48) Este artículo 205, que habla de autorización, para esa asunción de competencias por parte del Ministerio de la Gobernación, debe entenderse vigente incluso después de la creación del Ministerio de la Vivienda, pues la función de tutela organizativa está atribuida, sin variación, al Ministerio de la Gobernación. Acaso en el expediente podría intervenir el Ministerio de la Vivienda para informar sobre si los Ayuntamientos cumplieron o no sus obligaciones urbanísticas, pero el informe deberá referirse a resultados y no a aspectos de funcionamiento.

Gonźlez Pérez, J., en Comentarios a la Ley del Suelo, Madrid, 1967, entiende que la competencia subsiste en el Ministerio de la Gobernación, pues ano se trata propiamente de una potestad en materia urbanística, sino del ejercicio de una función de tutela para velar por la delimitación de competencia entre las distintas Entidades locales» (pág. 1076). La interpretación es distinta en el caso del artículo 206 (cfr. págs. 1077 y sigs).

(49) Sobre el concepto de licencias urbanísticas, vid. Gonzalez Pérez, J., aLicencias urbanísticas», en REVISTA DE ESTUdios DE LA VIDA LOCAL, núm. 154, cit., páginas 499 y sigs., y Vallina Velarde, J. L., aLicencias...», cit., en Revista de Derecho Administrativo y Fiscal, núm. 34, La Coruna, enero-abril 1973, págs. 5 y siguientes.

(50) Quizá pudiera hacerse una distinción que parece deducirse tanto de la Ley de 1956 como, mucho más, de la de 1975. Es la que se refiere a ordenación urbana y ordenación urbanística, dos términos frecuentemente intercambiados, pero que tienen individualidad y contenido singularizado. Cuando se habla de Planes de ordenación urbana no cabe duda que se pretende racionalizar la ciudad y su desarrollo como tal ciudad; pero cuando se habla de ordenación urbanística, lo que se ordena y pretende racionalizar es el territorio, si bien en función de la ciudad de que es tributario. Y hay que tener en cuenta que antes de la Ley 19/75, la de 1956 hablaba de ordenación territorial, que en definitiva era ordenación para la defensa del medio ambiente en el ámbito municipal o supramunicipal (cuando el Plan general abarcaba a más de un Municipio). La simple calificación de suelo rústico, que contenía un Plan general, significaba la sujeción de ese suelo a una serie de normas limitativas de protección que comportaban una defensa del medio físico contra las degradaciones de la extensión urbana. 
Planes generales clasificarán el suelo y definirán los elementos fundamentales de la estructura general adoptada para la ordenación urbanística del territorio, añade, en el número 2, que se someterán a los Planes Directores Territoriales de Coordinación, estableciendo la nueva Ley, en su artículo 9.0 ter, que entre las determinaciones generales deberán contenerse las «medidas para la protección del medio ambiente».

Ahora bien, como el artículo 9. provinciales la competencia para la redacción de los Planes generales cuando afecten a territorios de más de un Municipio, la función provincial se potencia desde este ámbito de ordenación, entrando directamente en la adopción o previsión de medidas de protección medioambiental a nivel de Plan general, como las pueden ejercitar a nivel de Plan Director según las determinaciones del párrafo $8 .^{\circ}$ bis de la propia Ley.

Para poder analizar hasta dónde puede llegar la actividad de control a través de las licencias, deberemos recurrir al análisis de lo preceptuado en el artículo 165 de la Ley de 1975, que establece: «Estarán sujetos a previa licencia, a los efectos de esta Ley, los actos de edificación y uso del suelo, tales como...». Quiere decirse que la enumeración del propio artículo 165 son ejemplos de entre los posibles actos sometidos a licencia. Cualquier otro no enumerado que afecte a edificación y uso de suelo también se someterá, o podrá someterse, a licencia, $\mathrm{y}$, partiendo de las determinaciones de los Planes, podríamos señalar, en lo que se refiere al medio ambiente, los siguientes:

\section{A) En el medio ambiente urbano}

a) Las obras de nueva planta.

b) Las modificaciones de la estructura y aspecto exterior de los edificios.

c) La modificación del uso de los edificios y construcciones.

d) La demolición de construcciones.

e) La primera utilización de nuevas construcciones.

f) Las obras e instalaciones que, de cualquier forma, afecten a conjuntos histórico-artísticos o urbanos, como serían la instalación de redes aéreas de suministro de energía eléctrica, conducciones telefónicas, etc. 


\section{B) En el medio ambiente rural}

a) .Las señaladas en el apartado anterior que se realicen fuera de los núcleos de población.

b) Las parcelaciones que no tengan el carácter de rústicas.

c) Los movimientos de tierras.

d) La tala de arbolado en cuanto afecte a paisajes protegidos o tenidos en cuenta al planificar.

e) El cambio de usos para comprobar si el nuevo es de los declarados incompatibles.

f) Cualesquiera otros actos que puedan provocar una degradación de elementos naturales o afectar al paisaje, tanto natural como de perspectivas de conjuntos urbanos contemplados desde el exterior.

Las licencias, así, deben dejar de ser simple control de edificaciones y usos en suelo lindante con vías públicas (51). para convertirse en control de estas actividades en cualquier lugar del término municipal. Y cuando las Diputaciones provinciales se subroguen en la competencia urbanística municipal, su actividad de intervención a través de la concesión de previa licencia deberá extenderse al control de cualquier acto de los particulares que comporte una construcción, en cualquier lugar, o una variación de uso o uso abusivo del suelo, cualquiera que sea el tipo de éste, y para comprobar su adecuación con los usos previstos en el Plan.

Las licencias entonces suponen una forma de controlar las actividades privadas que afectan de alguna manera al medio ambiente, control que puede ser más o menos efectivo, según se ejercite la facultad de intervención de la Administración en razón de esas actividades privadas, exigiendo la previa licencia en todo caso o solamente para núcleos de población.

(51) Corruptela que nace como consecuencia de la facultad de imponer tasas por expedición de licencias, a tenor de lo dispuesto en el artículo $440,7 .^{\circ}$, de la Ley de Régimen local, al preceptuar que podrán establecerse derechos y tasas por prestación de servicios públicos que beneficien especialmente a personas determinadas o se provoquen también especialmente por ellas, para construcciones y obras en terrenos sitos en poblados o contiguos a vías municipales fuera del poblado.

Este precepto ha hecho que en muchos Ayuntamientos se piense en la imposibilidad de exigir el sometimiento a previa licencia para construcciones fuera de poblado cuando no linden con vías municipales, provocando parte de la anarquía constructiva aparecida en el antiguo suelo rústico. 


\section{ASPECTOS CONCRETOS DE DEGRADACION DEL MEDIO AMBIENTE}

Para poder completar el estudio de las actividades que podría fiscalizar la Administración en defensa del medio ambiente, parece necesario hacer un análisis, aunque sea somero, de las actividades degradantes del medio y, en concreto, de cada uno de los elementos que lo integran.

Desde esta perspectiva podemos analizar:

\section{Polución de las aguas}

Se puede producir de muy diversas formas, entre las que cabe destacar:

- Contaminación nacida por vertido de aguas residuales no depuradas, tanto si son residuales domiciliarias como industriales.

- Contaminación como consecuencia de vertido de aguas procedentes de enfriamientos industriales que, al elevar la temperatura, modifican el medio natural, alterando el sistema ecológico de los cauces.

- Arrastre de plaguicidas y herbicidas debido a causas naturales (lluvias, corrientes subterráneas) o artificiales (canales de riego).

- Depósitos o arrastres sólidos, tales como tierras, basuras, embalajes (los plásticos, al no destruirse por el paso del tiempo, pueden provocar depósitos en determinados lugares de los cursos de agua).

- Vertido de agua conteniendo detergentes no biodegradables.

\section{Contaminación atmosférica}

Puede producirse por:

- Emanaciones de gases y humos nocivos procedentes de:

- Actividades industriales.

- Actividades. domésticas (calefacciones).

- Vehículos. 
- Emanaciones de calor con origen en las mismas fuentes.

- Falta de regeneración de oxígeno pór degradaciones producidas en el suelo, entre otras causas, por:

- Supresión de árboles en las ciudades.

- Limitación de parques y jardines.

- Tala de bosques.

- Sustitución de bosques de hoja caduca por coníferas.

\section{Degradación de los SUElos}

Producida por:

a) En el ámbito de los cultivos:

- Explotación intensiva.

- Explotación de tierras marginales, potenciándolas con fertilizantes químicos.

- Desforestización.

- Algunos efectos nocivos de la concentración parcelaria (52).

b) El problema de los desechos (53), que se concreta, principalmente, por la concurrencia de estas circunstancias:

(52) Al hacer desaparecer los setos de lindes, árboles, etc., produce una degradación del suelo como consecuencia de erosiones que podrían producirse al carecer de cortavientos, etc.

PERR0T, ob. cit., pág. 35, afirma: «En matière de remembrement certain travaux connexes trop systématiques, arasement de talus, arrachage de haies et plantations afférentes, non compensés par la création de rideaux d'arbres, de boqueteaux sur des parcelles libérées où ce serait possible (et prévu par la procédure du remembrement), compromettent l'équilibre écologique en créant des possibilités d'érosion, en altérant des microclimats sans parler de la disparition des oiseaux, etc. Il convient donc de prendre garde à ces excès en mettant l'accent sur ce qui, dans les procédures mêmes, permet de les eviter».

Desde otro punto de vista, Barbara WARD, ob. cit., pág. 124, al hablar de la contaminación de la tierra dice: $\alpha$... estas calamidades pueden complicarse más por la urbanización de la sociedad y por las formas cada vez más industrializadas de explotación animal, que eliminan a los hombres y a las bestias de sus puestos tradicionales en el ciclo agrícola. Si constantemente se les hace ingerir alimentos, en tanto que sus excrementos simplemente son arrastrados por el agua hacia los océanos, quemados en el aire o incluso "compactados" y sepultados bajo un "Monte del Basurero" resulta roto un ciclo fundamental de la Naturaleza: la devolución del nitrógeno natural al suelo del cual fue extraído por los cultivos. La capa labrantía, el humus y la textura del suelo están deteriorándose constantemente. En unos cuantos siglos más, o incluso en décadas, de esta clase de irracional explotación del suelo el hombre puede despertar un día para encontrar que ha dañado en forma irreparable la diminuta cubierta de suelo, que es todo lo que hay entre él y la roca desnuda de la litosferas.

(53) Según Barbara WARD, ob. cit., págs. 117 y 118, aLas cantidades de desechos son ya tan grandes que es difícil concebirlas. Las estadísticas más detalladas se 
- Defectuosos sistemas de recogida y eliminación (54).

- Acciones humanas negligentes por falta de una toma de conciencia respecto al problema (55), produciéndose:

- Un abandono de basuras en cualquier lugar, y

- Un abandono incontrolado de vehículos, maquinaria y electrodomésticos inservibles.

- Proliferación de envases no retornables, de materiales plásticos que no se descomponen por la acción de los elementos de la Naturaleza, manteniéndose permanentemente y precisando acciones concretas de recogida.

c) Edificaciones.

Con independencia de la degradación por ocupación de suelos posiblemente productivos, las más importantes degradaciones que puede producir una edificación incontrolada son:

- La visual, tanto en espacios urbanos (ocultando o modificando perspectivas) como en rurales (nocividad de la salpicadura de edificios de segunda residencia en el medio rural).

- La nacida de la congestión urbana que densifica, muchas veces sin haberlo tenido en cuenta, la producción de residuos sólidos y de aguas residuales.

- La que afecta directamente a la productividad de los suelos, como consecuencia de la emanación de polvo en edificaciones industriales.

refieren a los Estados Unidos. En 1920, el hogar promedio generaba 1,25 kg. de desechos sólidos al día. En 1970, esta cifra había aumentado a 2,4 kg. y para 1980 quizá llegue a $3,7 \mathrm{~kg}$. Si se agregan los desechos industriales -de las minas y fábricas-, la cifra per capita es cercana a $23 \mathrm{~kg}$. por dían.

(54) La diferente composición de las basuras o desechos sólidos, según sean indùstriales o domiciliarios, y la dificultad de separar las basuras ahúmedas» de las "secas» para un tratamiento diverso, encarecen los procesos de eliminación o reciclado de los residuos, obligando a adoptar medidas incluso legislativas.

En España existe, pendiente de discusión por el Legislativo, un proyecto de ley sobre «Industrialización de los residuos sólidos urbanos a través de la eliminación, recuperación o reciclado de sus materiales», publicado en el Boletín Oficial de las Cortes, núm. 1.430 , de 2 de mayo de 1975.

(55) «La lucha contra la contaminación exige fórmulas donde la sociedad se autocontrole y sean los mismos usuarios afectados quienes estén directamente interesados en defender su "marco de vida", sabiendo de antemano que cualquier degradación ambiental será restaurada a cargo de su patrimonio particular». Vid. F. Prieto GonzÁlez, a La actuación administrativa sobre el medio ambienten, en Boletin de Información del Ministerio de Obras Públicas, núm. 176, Madrid, 1972, página 12. 


\section{OTROS TIPOS DE DEGRADACIÓN}

Cabe entre ellos señalar las degradaciones, contaminaciones o poluciones de carácter sensorial, como son los ruidos, vibraciones, olores, etc., que no afectan a un elemento natural en especial, pero que producen una incidencia, ciertamente perjudicial, en las condiciones de vida humana.

Conviene tener en cuenta, en este aspecto, que la tecnología de la amortiguación de ruidos y vibraciones está en una situación incipiente, en donde las medidas posibles a adoptar resultan insuficientes.

En este orden de cosas, es reciente la disposición de nuestra Administración para el control de construcciones, sometiéndolas a normas de aislamiento térmico, aunque la razón directa de la disposición esté en función del ahorro en el consumo de energía (56).

\section{CONCLUSIONES}

De todo lo analizado se deduce que las Diputaciones provinciales están habilitadas legalmente para llevar a cabo una acción efectiva en la defensa del medio ambiente en el territorio al que extienden su jurisdicción.

Esta acción efectiva depende, como es lógico, del puesto que, en la jerarquización del cúmulo de competencias provinciales, se quiera atribuir a las medioambientales.

Pero conviene concluir destacando la función integradora que pueden desarrollar las Diputaciones provinciales, integración para la que ningún otro órgano de la Administración pudiera estar legitimado o capacitado.

La acción integral de defensa del medio ambiente en el ámbito provincial comporta:

a) Una acción de ordenación a través de los Planes Directores Territoriales de Coordinación y de los generales que afecten a más de un Municipio.

(56) El Decreto 1.490/1975, de 12 de junio (Boletín Oficial del Estado de 11 de julio), establece las medidas a adoptar en las edificaciones con objeto de reducir el consumo de energía. 
b) Una acción sustitutiva de la inactividad municipal.

c) Una acción directa de prestación, manteniendo unos equipos de defensa del medio, en las diversas manifestaciones en que tal defensa puede llevarse a cabo. Así, cabría pensar en centros comarcales de lucha contra el fuego, en centros de depuración de aguas, también de ámbito supramunicipal, en centros de tratamiento y destrucción de basuras, en servicios de control de planes, etc.

Ciertamente que estos servicios no se van a atribuir a las Diputaciones provinciales como competencia exclusiva y de prestación obligatoria, pero la situación supramunicipal que tiene el Ente local provincial le hacen el más idóneo para la prestación de esos servicios de interés general.

d) Una acción muy especial de educación y sensibilización respecto a los problemas de defensa del entorno urbano y rural.

Para desarrollar todas estas actividades, ciertamente se precisan dos condiciones fundamentales. La primera de ellas, referida a los aspectos económicos que las prestaciones comportan, debe ser resuelta de alguna forma por la Administración del Estado, atribuyendo los medios necesarios o complementarios. La segunda, de orden político, supone la toma de conciencia respecto a toda la problemática medioambiental por parte de los rectores del Ente local provincial.

Finalmente sería necesario dotar a las autoridades rectoras de la Diputación de la necesaria facultad sancionadora que fuera realmente coercitiva para que su actividad no quedara en mero programa imposible de hacer cumplir frente a los administrados. 